\title{
La Bibliotecología en la encrucijada del cambio de siglo
}

- I sigloXX seha caracterizado por cambios radicales y velocesa diferencia delascenturias pasadas, en las que éstos se presentaron de manera gradual, dando incluso lugar a amplios lapsos en los que no se registraban modificaciones notables y a profundidad. Tales cambios afectaron de una u otra forma la integridad detodos los campos del conocimiento. Fue en ese siglo cuando la multi, inter, e intra disciplina alcanzaron un importante desarrollo y propiciaron la especial ización y la integración de conocimientos, lo que produjo un mayor avance científico, tanto en el orden teórico como en el práctico, además de estrechar su interacción con la tecnología.

La fusión de la ciencia y la tecnología fue el medio concebido para el evar la calidad de vida delosindividuosy las sociedades, al mismo tiempo quemodificaba no sól o las actividades de la economía, la política y los servicios, sino que también irrumpía de manera determinante en la estructura interna de los cuerpos del conocimiento. Estos cambios en los planos científicos y tecnológicos se dieron acompañados de un proyecto económico global que configuró un nuevo orden social, comúnmente denominado la Aldea gdaal.

La aceleración de los cambios en el Siglo XX propició profundas reestructuraciones sociales que afectaron de manera radical incluso la vida cotidiana de los individuos y transformaron su estructura de pensamiento, su forma de anal izar la realidad objetiva del entorno y el lenguajeformal delas ciencias. Estoscambios contribuyeron a la rearticulación de las distintas estructuras sociales.

Tales circunstancias tuvieron eco al interior de los campos del conocimiento y, como consecuencia, en las actividades profesionales. Los paradigmas sobre los que se erigían los campos del conocimiento fueron afectados en sus propios fundamentos y esto los obligó a constituir nuevos paradigmas que les permitieran seguirse desarrollando y prepararse para el cambio de siglo.

Lo anterior alcanza especial agudeza en el campo bibliotecológico y de la información, dado su carácter inter y multidisciplinario. Esemismo carácter la haceen particular sensible no sólo al desarrollo desu propio sistema de conocimiento, sino quetambién debetomar en cuenta la dinámica, seriamente afectada, de los fenómenos sociales externos.

Con la publicación de este número, InvatigacónBi diđeedógcatiene como final idad pre sentar un conjunto de artículos que buscan ser una reflexión, desde distintos enfoques, so- 
bre aquellos fenómenos sociales que, como se enunció anteriormente, han afectado a las Ciencias Bibliotecológica y de la I nformación y a su propia actividad profesional. Se abordan aquí aquellos aspectos que desdeel siglo pasado han venido afectando al campo bibliotecológico y de la información y se anuncian como determinantes en el nuevo siglo.

Lostemas aquí reunidosabordan, entreestosfenómenos, a la globalización y a la infodiversidad, problemáticas que expresan dos movimientos de contrastes, uno de expansión y el otro de contracción, característica de la orientación de fin de siglo queen al guna medida ha situado a la actividad bibliotecaria y de la información ante el dilema de la unidad y lo diverso. Ante los cambios que deja la centuria se plantea de manera acucianteel problema dela tradición o la innovación del paradigma científico de la disciplina, lo que perfila la posibilidad de una nueva orientación teórica. Todo esto ha afectado a una práctica espećfica como la de la lectura y, por consiguienteal libro, y ha provocado una profunda crisisque afecta a ambos. El surgimiento de una nueva lengua franca a mediados del siglo pasado, también ha modificado la generación, el procesamiento, el acceso y el uso dela información, y acarreado cambios en las regularidades de la Comunicación Científica, sobretodo en aquéllasquesurgen en relación con el uso del idioma. En el plano nacional se hace pertinentela reflexión sobre una legislación que permita preservar el patrimonio documental, queha sido descuidado; su preservación es un reto para el nuevo milenio. D eigual forma el cambio en losparadigmas normativos dela organización documental se presenta como una tarea obligada para los al bores del siglo XXI, y deberá contrarrestar la influencia quetiendea ejercer la tecnología. Este entorno confluye en el más amplio espacio dela cultura y la sociedad, y constituye una nueva forma de organización social denominada Sociedad dela I nformación, quedalugar a fenómenos muy espećficos, como, entre otros, la literatura de masas.

El panorama presentado nos alerta sobre una diversidad de problemas que lejos de quedar resueltos o responder a una infinidad de supuestos nos enfrentan a ellos exigiéndonos una actitud crítica y abierta ante el quehacer científico del nuevo milenio.

Salvador G orbea-Portal H éctor G uillermo A lfaro-López 